\title{
DIAMOND LIKE CARBON (DLC) COATING ON CARBON STEEL WITH PLASMA TECHNIQUES FOR GAS PIPES
}

\author{
Ilham Nur Dimas Yahya ${ }^{1, a)}$, Djony Izak Rudyardjo', Jan Ady1) \\ ${ }^{1}$ Department of Physics, Faculty of Science and Technology, Universitas Airlangga Surabaya, East Java, Indonesia \\ a) Corresponding author: ilhamnurdimasyahya@gmail.com
}

\begin{abstract}
A study about coating on carbon steel by plasma technique aims to determine the variation of time and pressure on the hardness and corrosion strength of a material. The material used in this research was carbon steel with carbon chest of $0.245 \%$. This carbon steel was a plasma technique process with a temperature of $300 \mathrm{oC}$ and various pressure variations, such as 1.2 mbar; 1.4 mbar; 1.6 mbar; 1.8 mbar; And 2.0 mbar. The highest hardness was found at 1.8 mbar pressure, which was 161.7 VHN. Then set with a temperature of $300 \mathrm{oC}$ and a pressure of $1.8 \mathrm{mbar}$ and a time variation, which were 1 hour; 1.5 hours; 2 hours; 2.5 hours; 3 hours. The largest hardness value was obtained at 3 hours with a hardness value of 161.7 VHN. Then the corrosion test obtained the optimum value at 2 hours with a corrosion value of $0.69 \mathrm{mpy}$. This was because on the surface of carbon steel there was a layer of Diamond Like Carbon (DLC).
\end{abstract}

\section{INTRODUCTION}

Indonesia is the $10^{\text {th }}$ largest natural gas producing country with a total of 75.0 billion $\mathrm{m}^{3}$ and the $26^{\text {th }}$ largest natural gas consuming country with a total of 39.7 billion $\mathrm{m}^{3}$ in 2015 (BP Statistical Review of World Energy, 2016). Pipelines performed vital functions. The pipes were made of carbon steel, where any carbon steel could sustain corrosion. The corrosion rate of each carbon steel was different. In carbon steel, natural gas pipes could sustain corrosion ranging from 15-28 mpy due to the effect of dissolved $\mathrm{CO}_{2}$ (Fahrurrozi et al, 2009).

Overcoming the risk of corrosion, it was necessary to do material manipulation. Material manipulation purposed to produce new materials to had better properties (Mangiring, 2013). Carbon steel was steel with carbon as the main interstitial alloy ranging from $0.12-2.0 \%$. The material currently being developed by many researchers in surface coating is Diamond Like Carbon (DLC). Diamond Like Carbon (DLC) coating carbon in a material hence the carbon atom bound to $\mathrm{sp}^{3}$. Diamond Like Carbon (DLC) material had the properties of hardness, modulus of elasticity, negative electron affinity and inert both physically and chemically like diamond (Robertson, 2002). There were so many things that could be done to improve the mechanical properties of the surface of the material, such as using the surface treatment technique. Surface treatment was a treatment to improve the quality / quality of a material as desired. The plasma technique used the Chemical Vapor Deposition (CVD) method due to the material used was in the form of a gas, namely LPG gas. Methods to increase hardness and resistance to corrosion could be done by surface treatment techniques, namely plasma techniques with the Nitriding process using a DC glow-discharge plasma machine or commonly called a Nitriding machine and a Diamond Like Carbon (DLC) coating. This was done on the surface of carbon steel in order to increase its hardness and corrosion resistance.

The material used in this research was carbon steel with several variations, such as time, pressure, temperature and then analyzed using corrosion and hardness tests. Corrosion test purposed to prove the corrosion rate before and after the coating proces with Plasma technique used the Potentiostatic method and the hardness test indicated the hardness level of the carbon steel formed after the coating process with the Plasma technique using a micro vickers hardness tester. 


\section{EXPERIMENTAL METHOD}

This research was conducted in two stages, namely the literature study and the research. In the literature study, the authors looked for literacy, references and studied the plating that occured in carbon steel using plasma nitriding techniques with several different variations including temperature, pressure, time. In addition, the authors learned about Diamond Like Carbon (DLC) which was contained in the coating process. The information was obtained from various literatures, including related research journals, electronic books, the internet, explanations from supervisors, and knowledge. While attending the courses and field work practices. The next stage was the research stage, the first stage was the material preparation process. This first stage used a Polish machine and an Ultrasonic Cleaner machine. The second stage of the DLC coating process on carbon steel used a Nitriding machine. The third stage was the sample testing phase with a hardness test using a Michrohardness Tester machine and a corrosion test using the Potentiostat PGS-201T corrosion test kit strung up with a computer.

\section{RESULTS AND DISCUSSIONS}

\section{Hardness Test Result}

Before the treatment was carried out, the hardness test was performed first to determine the hardness value of the carbon steel, the hardness value was 108.1 VHN. This test was carried out with a load of 10 gf within 5 seconds.

Then the sample was treated with 5 different pressure variations.

TABLE 1. Hardness Value at Certain Pressure

\begin{tabular}{cccc}
\hline Weight & Time & Sample & Hardness Value (VHN) \\
\hline \multirow{4}{*}{10 gf } & 5 seconds & P1 $=1,2 \mathrm{mbar}$ & 114,2 \\
\cline { 3 - 3 } & & $\mathrm{P} 2=1,4 \mathrm{mbar}$ & 139,5 \\
\cline { 3 - 3 } & & $\mathrm{P} 3=1,6 \mathrm{mbar}$ & 151,4 \\
\cline { 3 - 3 } & & $\mathrm{P} 4=1,8 \mathrm{mbar}$ & 161,7 \\
\cline { 2 - 3 } & & $\mathrm{P} 5=2,0 \mathrm{mbar}$ & 117,8 \\
\hline
\end{tabular}

From the table above. The optimum value of the pressure range from 1.2 to 2.0 hours was obtained in the $\mathrm{P}_{4}$ sample, such as at 1.8 mbar with a hardness value of $161.7 \mathrm{VHN}$, then the next step was treating the sample with 5 time variations.

TABLE 2. Hardness Value at Certain Time

\begin{tabular}{lccc}
\hline Weight & Time & Sample & Hardness Value (VHN) \\
\hline \multirow{4}{*}{$10 \mathrm{gf}$} & 5 seconds & $\mathrm{T} 1=1,0$ hour & 119,7 \\
\cline { 3 - 4 } & & $\mathrm{T} 2=1,5$ hours & 123,3 \\
\cline { 3 - 4 } & & $\mathrm{T} 3=2,0$ hours & 137,5 \\
\cline { 3 - 3 } & & $\mathrm{T} 4=2,5$ hours & 152,7 \\
\cline { 2 - 3 } & & $\mathrm{T} 5=3,0$ hours & 161,7 \\
\hline
\end{tabular}

Treatment of carbon steel with plasma techniques by adding greater pressure did not lead the carbon steel had a higher hardness value, yet there was a saturation point in the treatment of various pressures which made carbon steel had the most optimum hardness value. This was due to the plasma glow discharge process where the carbon ions contained in the LPG gas hit the surface of the carbon steel and bond with $\mathrm{sp}^{3}$. Where the bond were obtained through a fairly moderate temperature process since it only required a temperature of $300^{\circ} \mathrm{C}$. The more carbon that bound to the surface of the carbon steel, the more $\mathrm{sp}^{3}$ was increasing. As the bond was a bond forming from diamond thus it had a higher hardness value when compared to the absence of a $\mathrm{sp}^{3}$ bond. By the plasma technique, new elements were added to the surface of the carbon steel.

In making pipes, generally using carbon steel with a hardness value of 108.1 VHN. Increasing the hardness value, a surface treatment was needed in order to obtain a higher hardness value. The surface treatment was carried out, therefore the sample did not sustain a change in the overall structure, only on the surface thus the carbon steel surface had increased quality. 
From the table above. The optimum value of the time range from 1.0 to 3.0 hours was obtained in the $\mathrm{T}_{5}$ sample, namely at 3.0 hours with a hardness value of 161.7 VHN.

\section{Corrosion Test Result}

Determining the value of the sample corrosion rate, the test was carried out using the potentiostatic polarization method. After starting the program on the potentiostat of the sample, a potential versus log current intensity curve was obtained. Potential versus log current intensity curve for 6 test materials, namely before treatment; 1 hour; 1.5 hours; 2 hours; 2.5 hours; and 3 hours on groundwater.

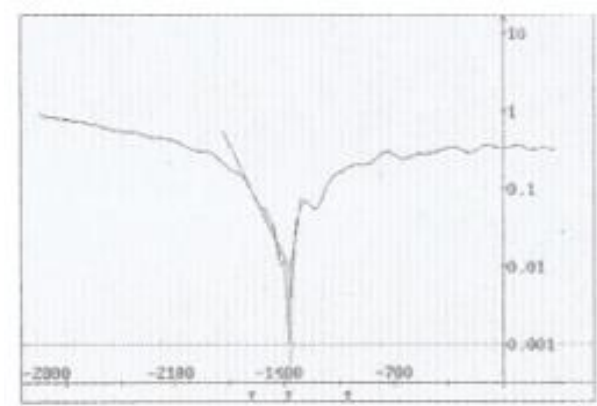

(a)

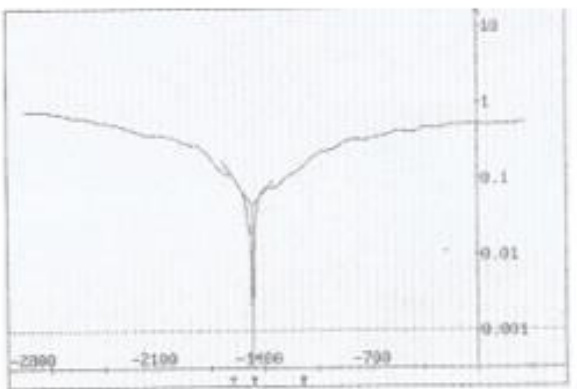

(c)

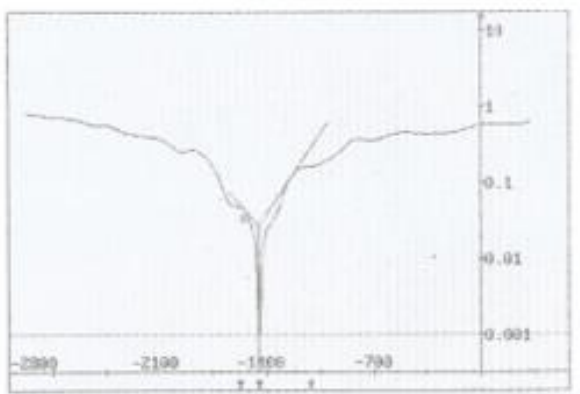

(e)

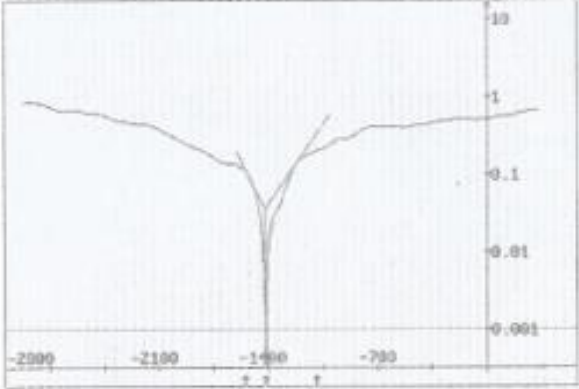

(b)

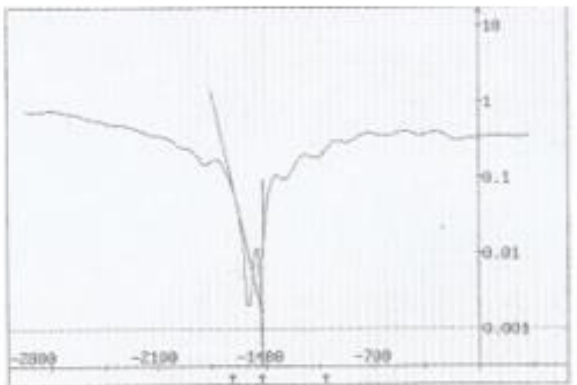

(d)

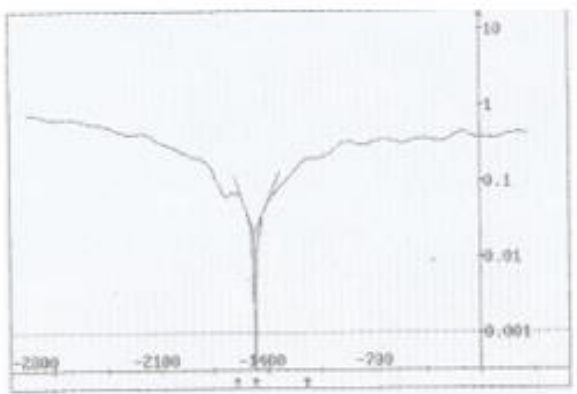

(f)

FIGURE 1. Curves the intensity of corrosion current with time during (a) before treatment, (b) 1 hour, (c) 1.5 hours, (d) 2 hour, (e) 2.5 hours, dan (f) 3 hours.

From this curve, the corrosion rate of each sample could be calculated using equation : Corrosion rate $(\mathrm{mpy})=$ $\frac{(0.13)\left(I_{c o r r}\right)(E W)}{d}$. The calculation results was the corrosion rate value of each sample in the test solution and represented in the following table : 
TABLE 3. Calculation Results of Corrosion Rate

\begin{tabular}{clcc}
\hline No & \multicolumn{1}{c}{ Sample } & Icorr $\left(\boldsymbol{\mu A} \mathbf{A} \mathbf{c m}^{2}\right)$ & Corrosion Rate $(\mathbf{m p y})$ \\
\hline 1 & $\mathrm{~T}=1$ hour & 33,76 & $20,19225345 \times 10^{-24}$ \\
\hline 2 & $\mathrm{~T}=1,5$ hours & 42,11 & $25,18648675 \times 10^{-24}$ \\
\hline 3 & $\mathrm{~T}=2$ hours & 1,51 & $0,903148776 \times 10^{-24}$ \\
\hline 4 & $\mathrm{~T}=2,5$ hours & 25,64 & $15,33558585 \times 10^{-24}$ \\
\hline 5 & $\mathrm{~T}=3$ hours & 19,28 & $47,41830134 \times 10^{-24}$ \\
\hline
\end{tabular}

Furthermore, a graph of the relation between the corrosion rate and the time change could be made as shown in the figure below:

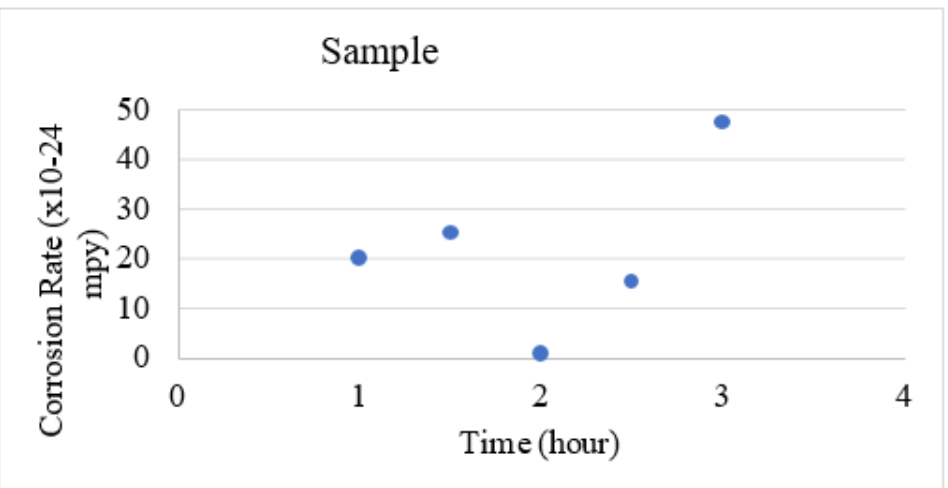

FIGURE 2. Graph of the relation between plasma techniques processing time and sample corrosion rate values.

In accordance with the graph above, the corrosion rate from $t=1$ hour to $t=1.5$ hours has increased then at $t=2$ hours the corrosion rate has decreased, this indicates that at $t=2$ hours is the optimal condition for the variation of time used. At $t=2.5$ hours and $t=3$ hours, the corrosion rate reincreased gain, this indicated that more than 2 hours it would lead the corrosion rate higher.

\section{CONCLUSION}

1. Plasma technique process with variation in time and pressure could improve the characteristic of carbon steel, including the hardness and corrosion rate of the sample.

2. The appropriate time during the plasma nitriding process for the hardness value is 3 hours, while the corrosion rate value was 2 hours due to the best characteristics of carbon steel for gas pipe application.

\section{REFERENCE}

1. Antaki, George A. 2003. Piping and Pipeline Engineering. Aiken, South Carolina, U.S.A.

2. Arifin, Y. 2014. Studi Kasus Laju Korosi pada Pipa API 5L di Energi Mega Persada. Jurnal Teknik Mesin : Universitas Negeri Semarang

3. ASME, 1995. ASME B.31-8. 1995 Edition : Transmission and Distribution Piping System. USA : ASME Chen, F.F. 1977. Introduction to Plasma Physics. Plenum Press : New York.

4. Departemen Energi dan Sumber Daya Mineral (ESDM). http://www.esdm.go.id/

5. Herberg, Mikkal. 2011. Natural Gas in Asia: History and Prospects. Pacific Energy Summit : Jakarta.

6. Konuma, M. 1992. Film Deposition by Plasma Techniques. Spinger Verlag : Berlin.

7. Liebermen, M.A. and Lighterberg, J.A. 1994. Prisciples of Plasma Discharges and Materials Processing. John Wiley and Sons, Inc : New York, Chichester, Birbane, Toronto, Singapore. 